\title{
Surface Properties of Suberin
}

\author{
Nereida Cordeiro, * Patrice Aurenty, $\neq$ Mohamed Naceur Belgacem, \\ Alessandro Gandini, $\neq^{\prime 1}$ and Carlos Pascoal Neto $\dagger$
}

\begin{abstract}
*Universidade de Madeira, Departamento de Química, 9000 Funchal, Portugal; †Universidade de Aveiro, Departamento de Química, 3800 Aveiro, Portugal; and $\$$ Matériaux Polymères Ecole Française de Papeterie et des Industries Graphiques (INPG), BP 65, 38402 St Martin d’Hères, France
\end{abstract}

Received September 9, 1996; accepted December 10, 1996

The surface energy of suberin was determined by four different methods, namely, (i) contact angle measurements, (ii) Wilhelmy plate measurements, (iii) maximum bubble pressure, and (iv) inverse gas chromatography (IG C ). The first three methods gave a $\gamma_{\text {sub }}$ value in the range $40-50 \mathrm{mN} \mathrm{m}^{-1}$ at room temperature. The major component of this value reflects the dispersive contribution. The IGC measurements showed a higher dispersive term, which is common with this method of characterization. The surface acid (A)/base (B ) properties were also evaluated, and the results indicated that suberin has an acidic character. 1997 Academic Press

Key Words: suberin; surface energy; contact angle; Wilhelmy plate; maximum bubble pressure; inverse gas chromatography.

\section{INTRODUCTION}

The cork from Quercus suber L. is used in many industrial applications such as cork stoppers and insulating boards, among others. During cork transformation, large amounts of cork powder are produced. This cork fraction has no industrial interest due to the small size of its particles and is frequently burned for energy production. However, cork powder can be an important source of chemicals, viz. mainly suberin (1) which is its most important constituent amounting to 30 to $50 \%$ by weight. In this context, the development of suitable applications for suberin could constitute an interesting way to valorize large amounts of a byproduct of the cork industry.

The structure of suberin in cork is not yet fully understood. Kolattukudy has proposed that suberin, as isolated from various vegetal products like potatoes, is a network containing both phenolic and long aliphatic moieties which are linked through ester groups, as shown in Scheme 1 (2): The phenolic part displays features similar to those of lignins and the aliphatic one is composed of fatty acid polyesters bearing free $\mathrm{OH}$ groups. In situ suberin is insoluble in all solvents but can be decrosslinked by alkaline hydrolysis or methanolysis. The main products resulting from this operation

\footnotetext{
${ }^{1}$ To whom all correspondence should be addressed.
}

applied to $Q$. suber L. are 2,2-dihydroxydocosanoic acid, 18-hydroxyoctadecanoic acid, 9,10-dihydroxyoctadecanoic acid, and 9,10,18-trihydroxyoctadecanoic acid (3).

The physico-chemical features of suberin are far from being completely characterized. To the best of our knowledge, no report has appeared as yet on the characterization of the surface properties of extracted suberin. This paper gives therefore the first results related to the surface energy and acid-base properties of a suberin sample extracted from cork by base-catalyzed methanolysis. Different methods were used for this purpose, namely the Wilhelmy plate, inverse gas chromatography, maximum bubble pressure and contact angle measurements. This study is part of a more comprehensive investigation on cork (4) and suberin aiming at a thorough unravelling of their structure and potential applications, particularly in the field of novel polymeric materials. The precise knowledge of the surface properties of suberin is particularly relevant to its possible use as an additive in coating formulations like printing inks and varnishes, a research topic presently in progress in our laboratory which dictated the systematic approach described here.

\section{MATERIALS AND METHODS}

\section{Isolation of Suberin}

As mentioned above, the suberin used in this work was obtained by the alkaline alcoholysis of a sample of highquality cork, kindly supplied by the Champcork Company. This procedure consisted on successive soxhlet extractions of the cork powder with methylene chloride, ethanol, and water. The extractive-free cork was dried and submitted to alkaline methanolysis with a solution of $0.1 \mathrm{M} \mathrm{KOH}$ in $\mathrm{MeOH}$, for $5 \mathrm{~h}$ with a solvent/cork ratio of $10 / 1 \mathrm{v} / \mathrm{w}$. The reaction medium was neutralized, extracted with chloroform and dried. After evaporation of chloroform, the residual organic products were considered as suberin which was a waxy paste-like material containing both a liquid and a microcrystalline phase, the latter possessing a melting range of 30$40^{\circ} \mathrm{C}$. The experimental conditions and physico-chemical 


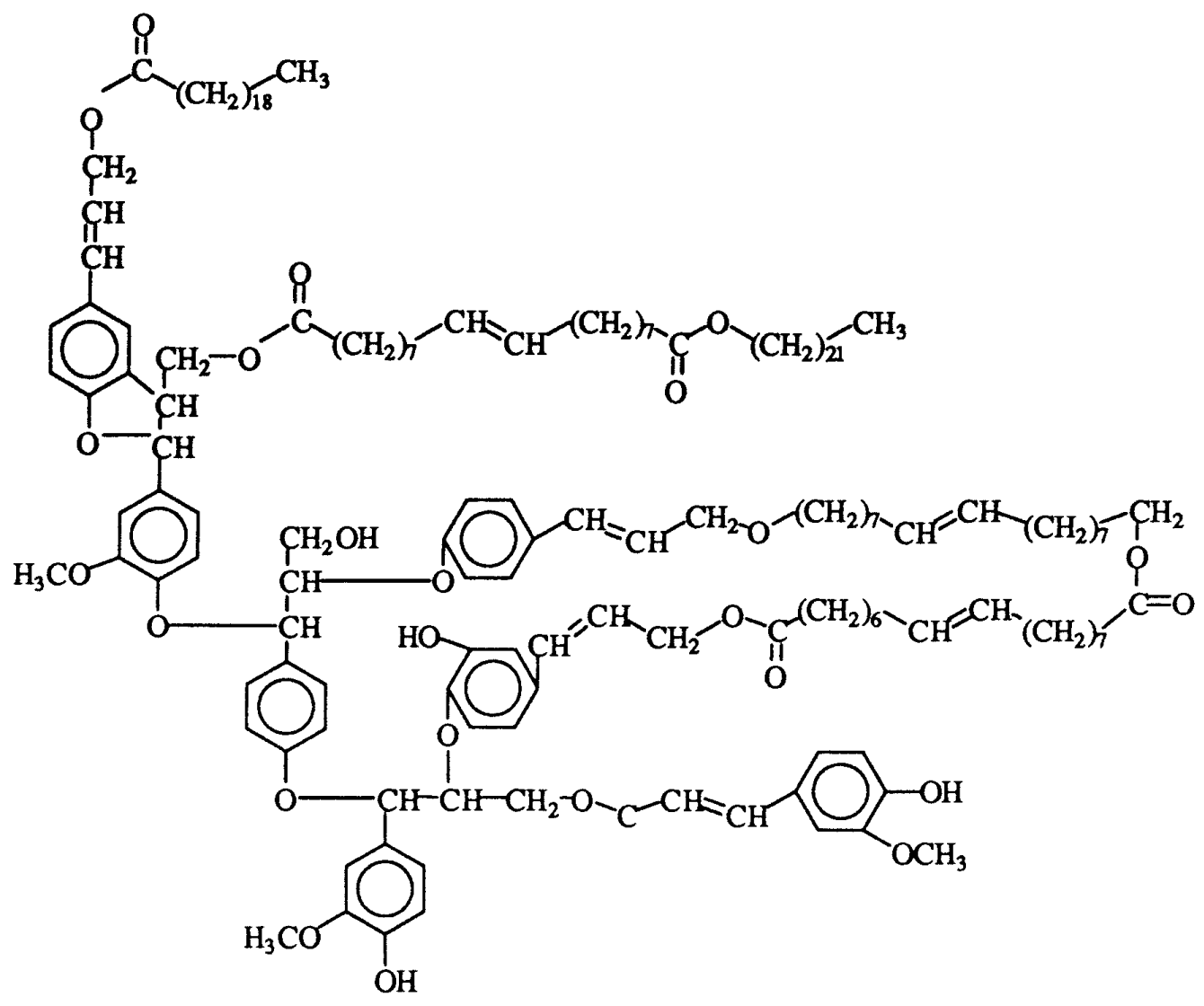

SCHEME 1

characterization of this product will be described in detail elsewhere (5) as well as those of cork lignin (6).

\section{Contact Angle Measurements}

The contact angle measurements were carried out with a goniometer constructed in our laboratory equipped with a CCD camera working at up to 200 images per second as described in a previous publication (7). The results were collected with a video-card and treated by image analysis software. The reproducibility was about $\pm 1^{\circ}$. Two reference surfaces, namely, glass and polyethylene, both thoroughly cleaned and submitted to a $6 \mathrm{~h}$ Soxhlet extraction with methanol, were used as alternative supports for suberin. Whereas the glass surface was coated with a $40 \mu \mathrm{m}$ layer of suberin using a spreading rod, the thickness of the layer on polyethylene (PE) was much higher, viz. ca. $500 \mu \mathrm{m}$, because of its bad wettability with suberin. After that, the surfaces were placed in a thermostated oven at $60^{\circ} \mathrm{C}$ for $30 \mathrm{~min}$ in order to induce a smooth and flat surface of substrate. Drops of various test liquids were deposited on these conditioned suberin surfaces in order to acquire values of contact angle relative to polar and non-polar as well as acidic or basic substances. Table 1 gives the specific properties of these liquids, namely their surface tension $\gamma_{\mathrm{L}}$ and the corresponding dispersive contribution $\gamma_{\mathrm{L}}^{\mathrm{D}}$.

\section{Wilhelmy Plate Measurements}

A Dognon Abribat Wilhelmy plate tensiometer $( \pm 0.5 \mathrm{mN}$ $\mathrm{m}^{-1}$ ) was used in order to measure the surface tension of liquid suberin. The experiments were carried out between 50 and $120^{\circ} \mathrm{C}$, i.e., above the melting temperature of suberin, after $2 \mathrm{~h}$ of thermal stabilization. In that temperature domain the viscosity was sufficiently low $\left(\eta=0.47 \mathrm{~Pa} \mathrm{~s}\right.$ at $\left.50^{\circ} \mathrm{C}\right)$ to ensure reliable results.

\section{Maximum Bubble Pressure}

A Sensadyne 6000 maximum bubble pressure tensiometer $( \pm 0.1 \mathrm{mN} / \mathrm{m})$ was used to measure the surface tension of suberin. The bubble frequency was about $1 \mathrm{~Hz}$, which corresponds to "semi-dynamic" conditions. The experiments were carried out at temperatures ranging from 57 to $86^{\circ} \mathrm{C}$ with inverted capillary probes in order to minimize possible artefacts arising from the relatively high viscosity of the medium. At each temperature, the tensiometer was recalibrated with water and methanol. 
TABLE 1

Relevant Characteristics of Solvents and Probes $U$ sed in This Investigation

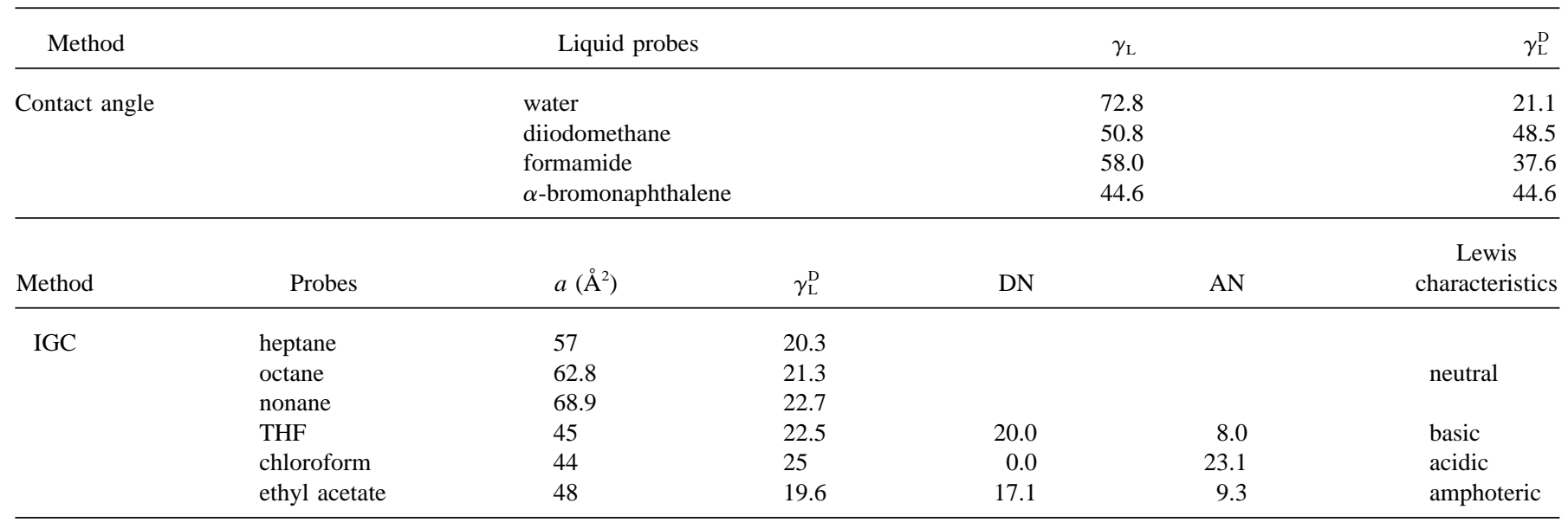

Note. $\gamma$ values in $\mathrm{mN} \mathrm{m}^{-1}$.

\section{IGC Measurements}

IGC experiments were carried out using a DELSI 121 DFL chromatograph equipped with a flame ionization detector and a $28 \mathrm{~cm} \times 4 \mathrm{~mm}$ pyrex column. About $1 \mathrm{~g}$ of suberin was adsorbed on chromosorb $\mathrm{W}$ sililated powder $(60 / 80$ mesh) and the column filled and conditioned overnight at $100^{\circ} \mathrm{C}$ in a stream of dry nitrogen. The dispersive component of the surface energy of suberin was obtained from results related to the injection of a series of $n$-alkane probes. The acid/base properties were estimated using tetrahydrofuran (basic), chloroform (acidic) and ethyl acetate (amphoteric) as probes. The relevant characteristics of these probes, i.e., the dispersive component of their surface tension in the liquid state $\gamma_{\mathrm{L}}^{\mathrm{D}}$, their molecular surface (a) and their Gutmann's donor (DN) and acceptor (AN) numbers (8), are given in Table 1. Propane was used as a marker, and the carrier gas was pure nitrogen.

Zero coverage conditions were reached by injecting $5 \mu \mathrm{l}$ of vapors of the different probes. In these conditions the interactions between adsorbate molecules themselves are negligible and the thermodynamic parameters, calculated using the retention time of each probe, depend only on the adsorbate/adsorbent interactions. Experiments were carried out repeatedly (and reproducibly) at five different temperatures, namely $50,60,70,80$, and $90 \pm 0.5^{\circ} \mathrm{C}$.

\section{Probes and Solvents}

All probes and solvents used for the different surface characterizations described above were commercial products of very high purity. The glass surface was a microscope slide and the polyethylene was a special sample without any additive kindly prepared for us by BP Chemicals, Lavera, France.

\section{Principle of IGC Calculations}

The dispersive component of the surface energy of a solid surface, $\gamma_{\mathrm{S}}^{\mathrm{D}}$, and its acidic, $K_{\mathrm{A}}$, and basic, $K_{\mathrm{B}}$, numbers were obtained following the classical procedure described in detail elsewhere (9). Only the general approach will be presented here.

The dispersive component of the surface energy, $\gamma_{\mathrm{S}}^{\mathrm{D}}$, is given by Eq. [1]:

$$
R T \ln V n=2 N\left(\gamma_{\mathrm{S}}^{\mathrm{D}}\right)^{1 / 2} a\left(\gamma_{\mathrm{L}}^{\mathrm{D}}\right)^{1 / 2},
$$

where $R$ is the gas constant, $T$ the working temperature, $V n$ the retention volume, $N$ Avogadro's number, $a$ the probe's molecular surface, and $\gamma_{\mathrm{L}}^{\mathrm{D}}$ the dispersive component of surface tension of the probe in the liquid state. $\gamma_{\mathrm{S}}^{\mathrm{D}}$ values are calculated accordingly.

$K_{\mathrm{A}}$ and $K_{\mathrm{B}}$ were obtained by carrying out experiment at least at three different temperatures. First, the specific free energy $\Delta G_{\mathrm{sp}}$ for the interaction between the polar probe and the suberin surface was determined using Eq. [2]:

$$
\Delta G_{\mathrm{sp}}=R T \ln V n-R T \ln V n_{\mathrm{ref}},
$$

where $V n$ is the retention volume of the polar probe and $V n_{\text {ref }}$ the retention volume related to the $n$-alkanes.

Then, the specific enthalpy $\Delta H_{\mathrm{sp}}$ was obtained as the slope of the plot $\Delta G_{\mathrm{sp}} / T$ vs $1 / T$ (Eq. [3]).

$$
\frac{\Delta G_{\mathrm{sp}}}{T}=\frac{\Delta H_{\mathrm{sp}}}{T}-\Delta S_{\mathrm{sp}}
$$

Finally, $K_{\mathrm{A}}$ and $K_{\mathrm{B}}$ were calculated from the slope and 


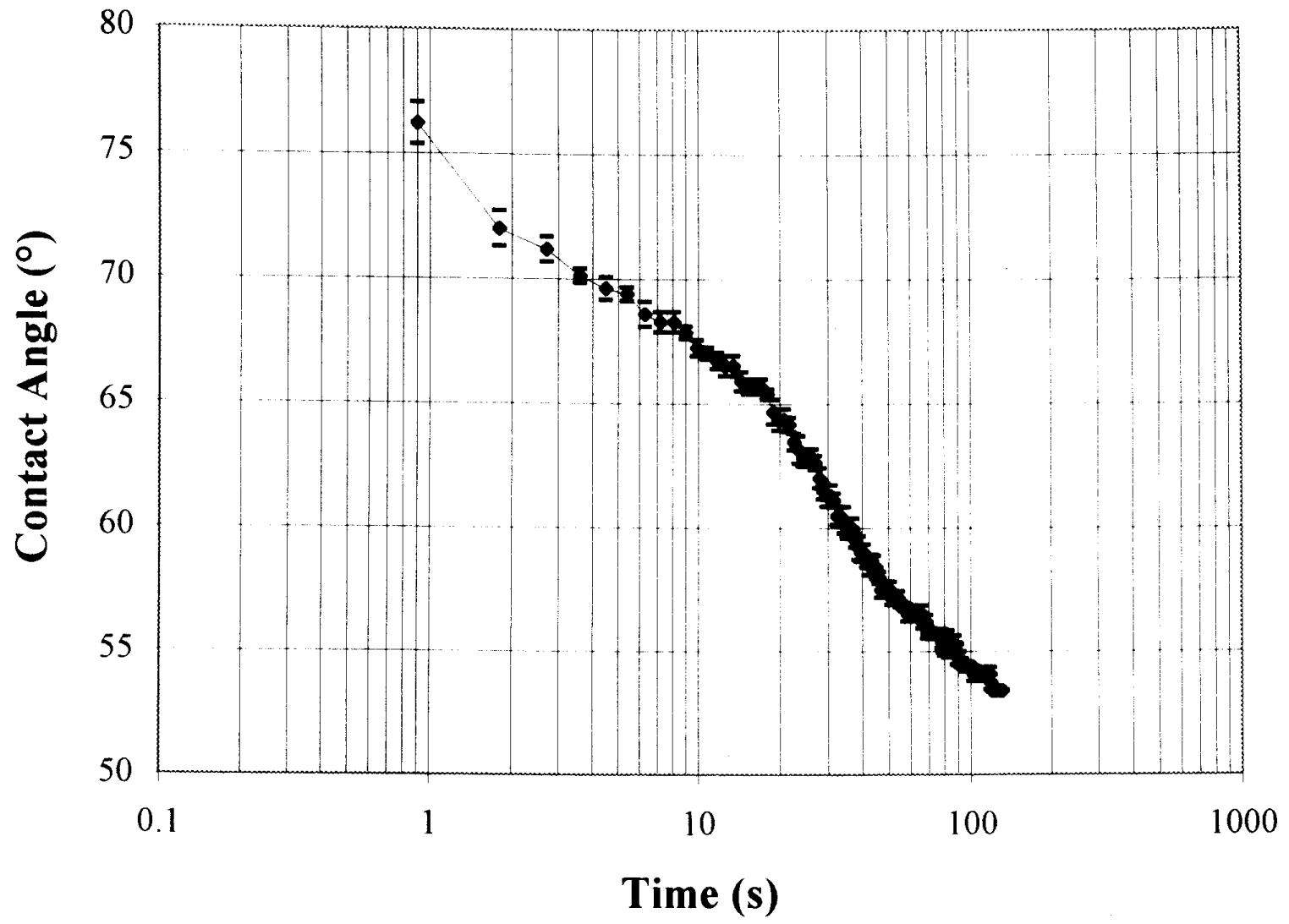

FIG. 1. Long-time evolution of the water contact angle for three wetting kinetics on the suberin surface (glass support).

the intercept of the plot of $\Delta H_{\mathrm{sp}} / \mathrm{AN}$ vs DN/AN following Eq. [4]:

$$
\frac{\Delta H_{\mathrm{sp}}}{\mathrm{AN}}=K_{\mathrm{A}} \frac{\mathrm{DN}}{\mathrm{AN}}+K_{\mathrm{B}}
$$

Here DN and AN are, respectively, Gutmann's (8) donor and acceptor numbers corresponding to the polar probes.

\section{RESULTS AND DISCUSSION}

\section{Contact Angle Measurements}

The apparent contact angles of water droplets were recorded over a period of time of $100 \mathrm{~s}$, with a frequency of 1 image/s. Figure 1 shows a typical time evolution and the standard deviation observed over three wetting kinetics experiments. A major common feature is that this evolution reflected a decrease of about $25^{\circ}$ within $100 \mathrm{~s}$. When such a phenomenon is observed, it is common to extrapolate the data at $t=0$ and then apply the Young equation. But with such a steep decrease of $\theta$ with time (Fig. 1), it was difficult to extrapolate our data reliably to $t=0$. This is why it was decided to carry out some experiments at very short times after the drop deposition, namely, every $5 \mathrm{~ms}$ after contact time using a homemade fast camera apparatus capable of acquiring 200 images per second (7). Figure 2 shows the typical evolution within these short spans of the contact angle of four different liquids on a suberin layer coated on glass and PE.

The first observation related to these fast data-acquisition mode, is that the decrease in the $\theta$ values thus recorded always began after 30 to $50 \mathrm{~ms}$, depending on the liquid. Because the suberin layer was flat and non-porous, the evolution of the contact angle as a function of time could be attributed to the following phenomena: (i) deformation of the contact line because of the low Young modulus of the material, (ii) diffusion of the probe into the suberin layer. The possible evaporation of the liquids is not taken into account here because of their low volatility and the short time scale of the experiments. Furthermore, considering the relatively high surface tension of the probes used in this study (water, $72.8 \mathrm{mN} \mathrm{m}^{-1}$; formamide, $58 \mathrm{mN} \mathrm{m}^{-1} ; \alpha$ bromonaphthalene, $44.6 \mathrm{mN} \mathrm{m}^{-1}$; diiodomethane, $50.8 \mathrm{mN}$ $\mathrm{m}^{-1}$ ), spontaneous spreading on suberin, which is likely to be a low surface-energy material, is not expected to occur on thermodynamic grounds.

This assumption was indeed verified because suberin was found to be insoluble in water and negligibly soluble in 


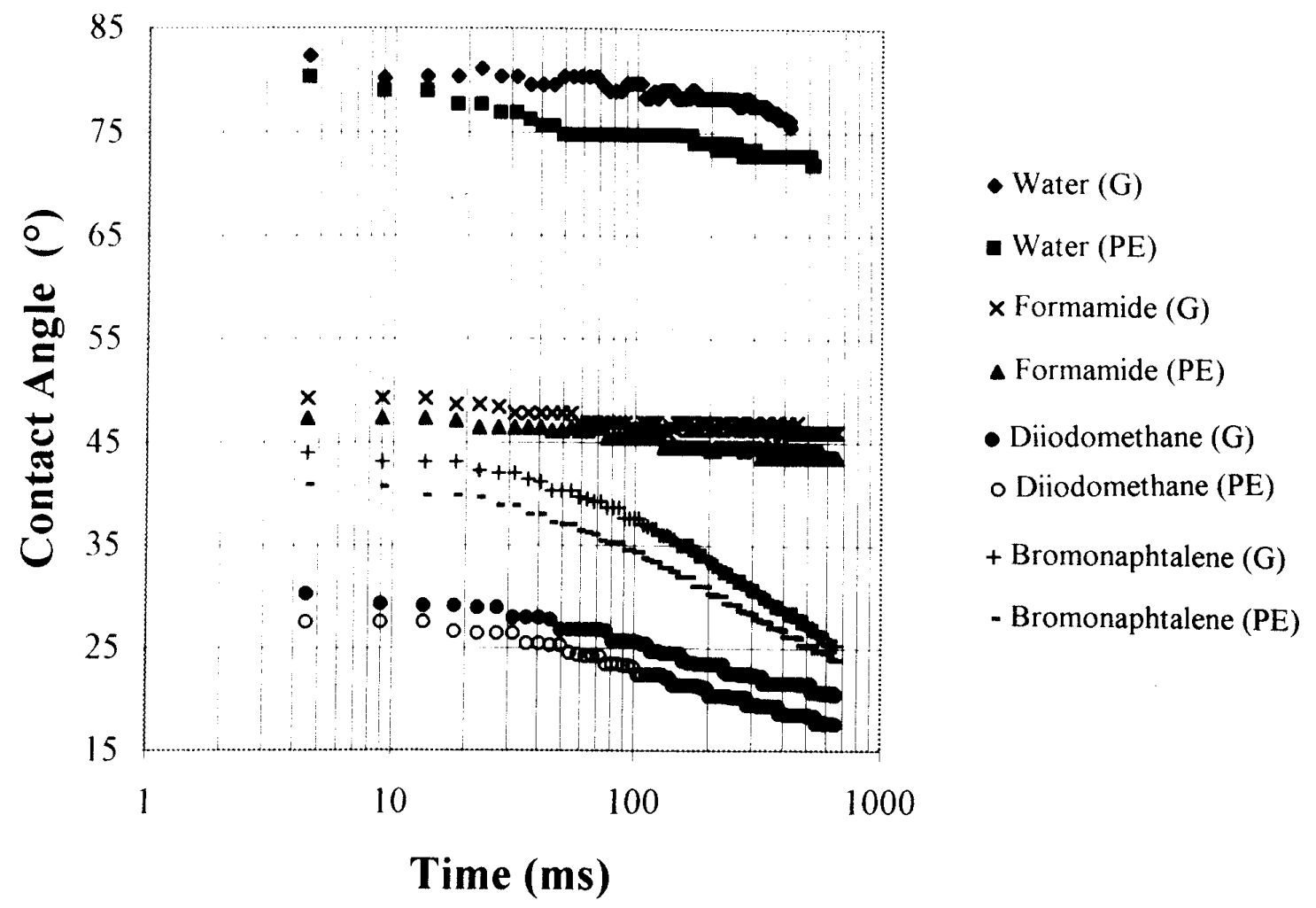

FIG. 2. Short-time wetting kinetics for four liquid probes: (G) glass support; (PE) polyethylene support.

formamide and diiodomethane within the times required for the measurements. Thus, the decrease in contact angle observed for these liquids (Fig. 2) was attributed to the deformation of the contact line (10) and was confirmed by a close observation by optical microscopy of the interface. The modulus of suberin was measured by a dynamic mechanical test on a Metravib apparatus working at room temperature between 5 and $100 \mathrm{~Hz}$, and was found to be in the range of $10^{5} \mathrm{~N} \mathrm{~m}^{-2}$. This value is 4 orders of magnitude lower than that associated with the onset of a rigidity sufficient to avoid deformation of the contact line (10). The possible role of the difference in density between the various liquids deposited and suberin was not taken into account, but we feel that it should not be too important.

Suberin was found to be soluble in $\alpha$-bromonaphthalene. The decrease in the contact angle observed with this solvent was thus attributed both to the deformation of the suberin layer near the contact line and to the diffusion of the solvent in the substrate. This interpretation is reinforced by the fact that the slope of the $\theta$ vs time plot obtained with $\alpha$-bromonaphthalene was much higher than those registered with the other liquids (Fig. 2).

The second observation made in the short-time experiments was that there is a systematic shift of about $2^{\circ}$ between the contact angles measured on the suberin layer coated on glass and those recorded from coatings done on PE. The explanation based on a possible effect of the chemical com- position of the support cannot be envisaged in the present context because of the large thickness of the suberin layer ( $40 \mu \mathrm{m}$ on glass and $500 \mu \mathrm{m}$ on PE) which was more than sufficient to screen the interactions between the liquid drops and the support material. Furthermore, if these interactions had been relevant, the shift observed for water would have been inverted because the glass surface is much more hydrophilic than the PE surface and, moreover, here the thickness of the suberin layer was lower on glass. The fact that $\theta$ remained higher with a glass support rules out the possibility of long-range interactions between water (and therefore also other liquids) and the base materials through the suberin layer.

The systematic downshifts of about $2^{\circ}$ for the thicker suberin layer is most likely attributed to a better ability of a thicker layer of that soft material to be deformed by an external stress.

Before proceeding to calculate surface energies by different classical methods, one final question has to be answered: Which contact angle should be taken as the "real" Young contact angle? An enticing idea is to take the value of the wavy plateau observed during the first $30-50 \mathrm{~ms}$, but this requires a preliminary check that the droplet has had sufficient time to reorganize itself in terms of thermodynamic criteria. To verify this point we proceeded as follows: (i) the approximative self-diffusion coefficients of the different solvents were calculated according to the Einstein-Stokes equation as 


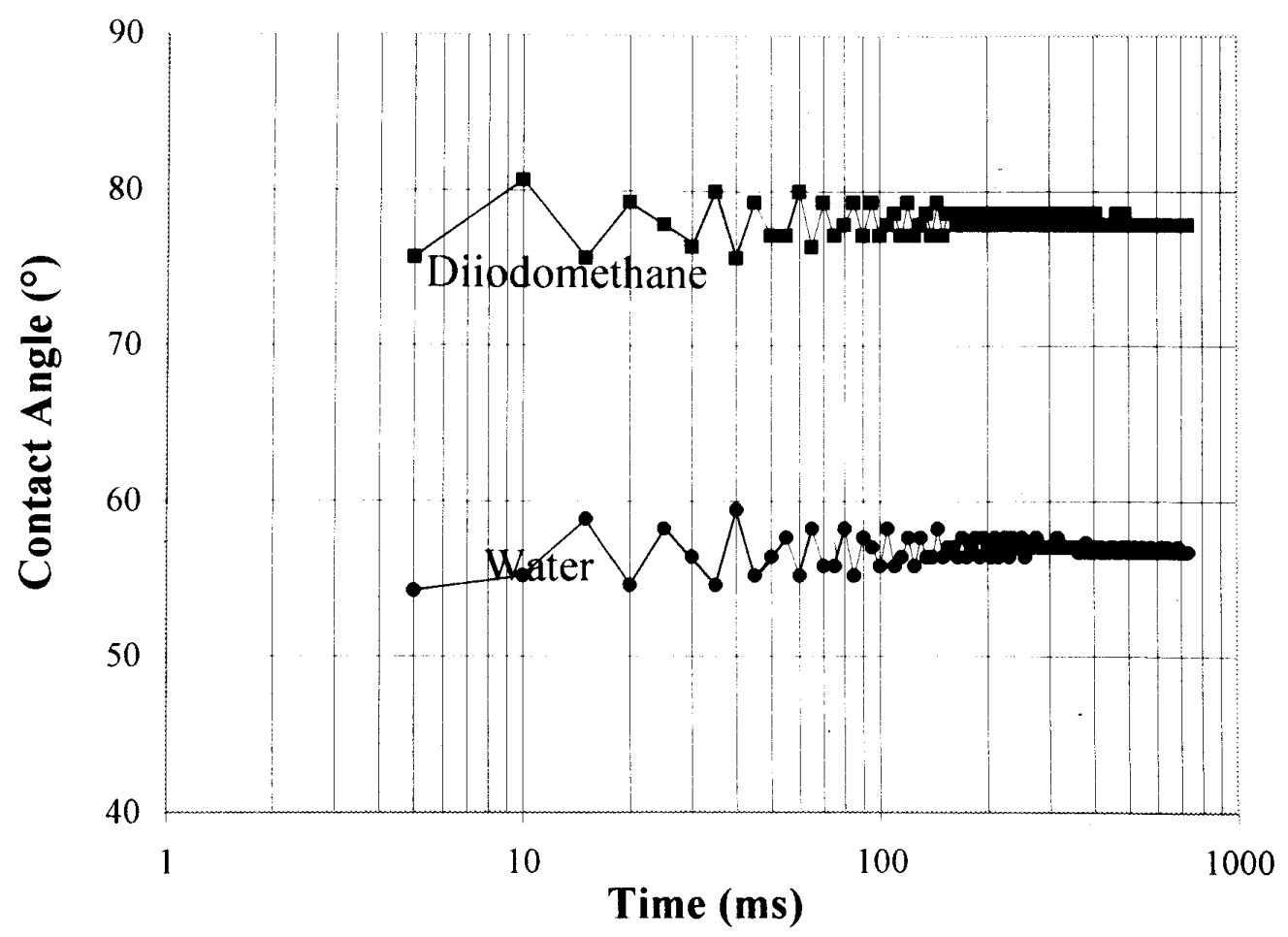

FIG. 3. Short-time oscillation for two liquid probes on an anodized aluminium surface.

(in $\mathrm{cm}^{2} \mathrm{~s}^{-1}$ ) $2 \times 10^{-5}$ for water, $4 \times 10^{-6}$ for $\alpha$-bromonaphthalene, $3 \times 10^{-6}$ for formamide, and $2 \times 10^{-5}$ for diiodomethane; (ii) the oscillations of bouncing drops of the four liquids on a high-modulus material, viz. anodized aluminium oxide contaminated by atmospheric impurities, were recorded. Each drop was slowly generated at the tip of a microsyringe needle and maintained at a distance of about $1 \mathrm{~mm}$ from that substrate during volume increase, until it detached itself under its own weight. The volume of the detached drops was in the range of 5 to $10 \mu \mathrm{l}$. The oscillations of the newly deposited drop are produced by the kinetic energy acquired during its fall. The characteristic oscillation periods recorded with our liquids were from 10 to $15 \mathrm{~ms}$ (Fig. 3). By comparison with the molecular movements associated with the data in given above, it was therefore concluded that the drops have enough time to reach thermodynamic equilibrium with their environment. This is also true of course of drops falling on suberin, which produce much more attenuated oscillations as shown in Fig. 2 because their kinetic energy is more readily shared with that soft material.

These verifications justify the decision of taking as the Young contact angle the mean value observed for each liquid on the oscillating plateau during the first $30-50 \mathrm{~ms}$. Moreover, since the thick layer of suberin was certainly more subject to deformation near the contact line, the values obtained on the thin layer deposited on the glass support were considered as more reliable in the following calculations and discussions.

\section{Fowkes' Approach}

Although $\alpha$-bromonaphthalene would have been the most adequate probe in this context for a purely dispersive liquid, the fact that it showed good solvent properties for our substrate made the corresponding values of contact angle suspicious. We therefore preferred to use the data obtained with diiodomethane, assuming in the first approximation that this liquid was essentially dispersive in character (see Table 1). Thus, the adhesion energy $W_{\mathrm{a}}$ between these materials could be expressed as the geometric mean involving the dispersive contribution to the surface energy of suberin and the actual surface tension of diiodomethane, viz.:

$$
W_{\mathrm{a}}=\gamma_{\mathrm{L}}(1+\cos \theta)=2\left(\sqrt{\gamma_{\mathrm{sub}}^{\mathrm{D}} \gamma_{\mathrm{L}}}\right)
$$

Table 2 gives the values of $\gamma_{\text {sub }}^{\mathrm{D}}$ obtained by this procedure applied to the two different supports.

The value of $80^{\circ}$ obtained for water suggests some hydrophilic interactions at the interface. Fowkes' non-dispersive interaction parameter, $I_{\mathrm{sl}}$, reflecting the non-dispersive contribution to the energy of adhesion, can be calculated as follows:

$$
\begin{aligned}
I_{\mathrm{sub} / \mathrm{H}_{2} \mathrm{O}} & =W_{\mathrm{a}}-W_{\mathrm{a}}^{\mathrm{D}} \\
& =\gamma_{\mathrm{H}_{2} \mathrm{O}}(1+\cos \theta)-2\left(\sqrt{\gamma_{\text {sub }}^{\mathrm{D}} \gamma_{\mathrm{H}_{2} \mathrm{O}}^{\mathrm{D}}}\right) .
\end{aligned}
$$


TABLE 2

Surface E nergy ( $\mathrm{mN} \mathrm{m}^{-1}$ ) According to the Fowkes, Owens- Wendt, and V an Oss Approaches

\begin{tabular}{|c|c|c|}
\hline \multirow{2}{*}{$\begin{array}{c}\text { Theoretical } \\
\text { approach }\end{array}$} & \multicolumn{2}{|c|}{ Probe surfaces } \\
\hline & Glass & PE \\
\hline \multicolumn{3}{|l|}{ Fowkes } \\
\hline $\begin{array}{l}\gamma_{\mathrm{sub}}^{\mathrm{D}} \\
I_{\mathrm{sl}}\end{array}$ & 43.1 & 43.9 \\
\hline water & 31.1 & 32.9 \\
\hline formamide & 15.6 & 16.3 \\
\hline \multicolumn{3}{|l|}{ Owens-Wendt } \\
\hline$\gamma_{\mathrm{sub}}^{\mathrm{D}}$ & 37.3 & 38.1 \\
\hline$\gamma_{\mathrm{sub}}^{\mathrm{P}}$ & 4.2 & 4.7 \\
\hline$\gamma_{\text {sub }}$ & 41.5 & 42.8 \\
\hline \multicolumn{3}{|l|}{ Van Oss } \\
\hline$\gamma_{\mathrm{sub}}^{\mathrm{LW}}$ & 44.6 & 45.4 \\
\hline$\gamma_{\mathrm{sub}}^{\mathrm{AB}}$ & 3.6 & 3.8 \\
\hline$\gamma_{\text {sub }}^{-}$ & 10.6 & 12.0 \\
\hline$\gamma_{\text {sub }}^{+}$ & 1.2 & 1.2 \\
\hline
\end{tabular}

The values obtained for this parameter are reported in Table 2. First of all, it became obvious that the differences observed between experiments performed on the thin layer (coated on glass) and the thick one (coated on PE) are negligible, namely less than $4 \%$.

The $I_{\mathrm{sl}}$ value obtained with water represents more than one third of the total energy of adhesion. This important contribution is clearly related to the presence of some $\mathrm{OH}$ and $\mathrm{COOH}$ functions in the structure of suberin, which can establish occasional hydrogen bonds with water.

\section{Owens-Wendt's Approach}

Owens and Wendt extended Fowkes' approach to the nondispersive (polar) part of the energy of adhesion. They assumed that the geometric mean approach is also applicable to that specific contribution, i.e.:

$$
W_{\mathrm{a}}=\gamma_{\mathrm{L}}(1+\cos \theta)=2\left(\sqrt{\gamma_{\mathrm{sub}}^{\mathrm{D}} \gamma_{\mathrm{L}}^{\mathrm{D}}}\right)+2\left(\sqrt{\gamma_{\mathrm{sub}}^{\mathrm{P}} \gamma_{\mathrm{L}}^{\mathrm{P}}}\right)
$$

This point is questionable because the geometric mean seems to be irrelevant for short-distance interactions like hydrogen bonding. Some examples of aberrations observed with this approach were given by Fowkes (11). Despite their controversial character (11-13), it seemed interesting to report here, for the sake of comparison with other polymeric materials, the values of $\gamma_{\text {sub }}^{\mathrm{D}}$ and $\gamma_{\text {sub }}^{\mathrm{P}}$ obtained for suberin with this treatment.

Figure 4 shows a typical Owens-Wendt's diagram related to the four probes. Table 2 summarizes the values of both contributions to the surface energy of suberin. Although the value obtained for $\gamma_{\text {sub }}^{\mathrm{D}}$ is lower than that calculated with

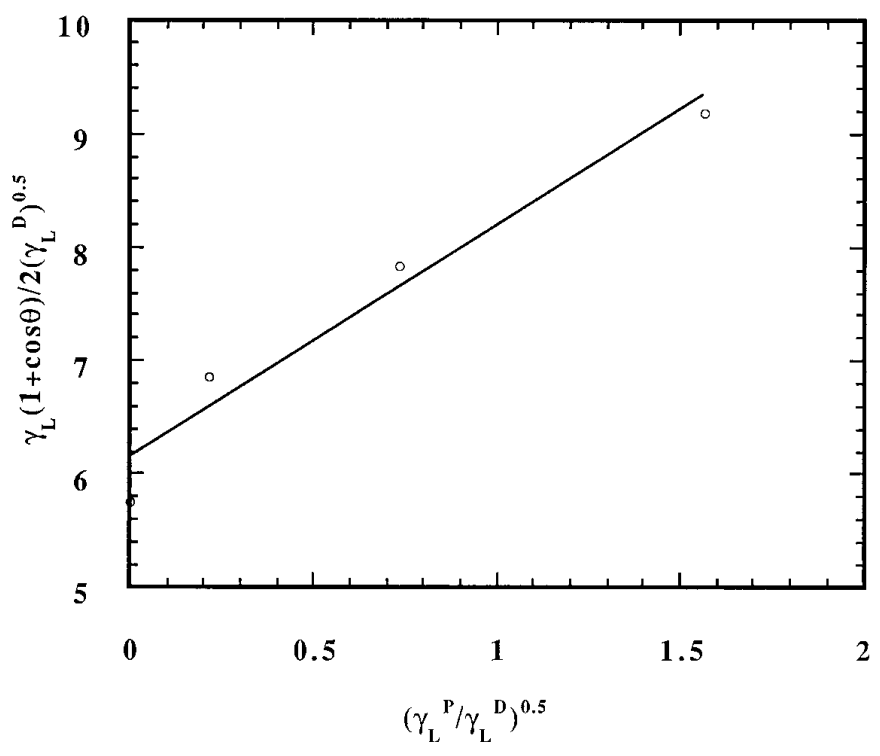

FIG . 4. Owens-Wendt's diagram related to four liquid probes on the suberin surface.

diiodomethane according to Fowkes' equation, the polarity of the suberin surface was found again to be relatively high, confirming the non-negligible Fowkes' $I_{\mathrm{sl}}$ value calculated with water (Table 3 ). The total surface energy of suberin reached a value of $41.5 \mathrm{mN} \mathrm{m}^{-1}$, which seems reasonable considering the structure of the suberin macromolecules (see Chart 1) with its occasional polar groups.

\section{Van Oss Approach}

The latter two approaches did not discriminate between polar and acid/base interactions. It seemed interesting to verify whether suberin, which contains some carboxylic groups, displayed a certain surface acidity. In that context, the experimental values of the contact angles, obtained with two polar probes (water and formamide) and a non-polar liquid (diiodomethane), were processed according to Van Oss' approach, namely:

$$
\gamma_{\text {sub }}=\gamma_{\text {sub }}^{\mathrm{LW}}+\gamma_{\mathrm{sub}}^{\mathrm{AB}}=\gamma_{\mathrm{sub}}^{\mathrm{LW}}+\sqrt{\gamma_{\mathrm{sub}} \gamma_{\mathrm{sub}}^{+}}
$$

where $\gamma_{\text {sub }}^{\mathrm{LW}}$ is the Lifshitz-Van der Waals contribution and $\gamma_{\text {sub }}^{\mathrm{AB}}$ the acid-base contribution to the surface energy (14).

TABLE 3

Dispersive Component of the Surface Energy of Suberin at D ifferent Temperatures, as Obtained by IGC

$T\left({ }^{\circ} \mathrm{C}\right)$

\begin{tabular}{lccccc}
\cline { 2 - 5 } & 50 & 60 & 70 & 80 & 90 \\
\hline$\gamma_{\text {sub }}^{\mathrm{D}}\left(\mathrm{mN} \mathrm{m}^{-1}\right)$ & 44.1 & 42.1 & 41.4 & 39.5 & 37.3 \\
\hline
\end{tabular}




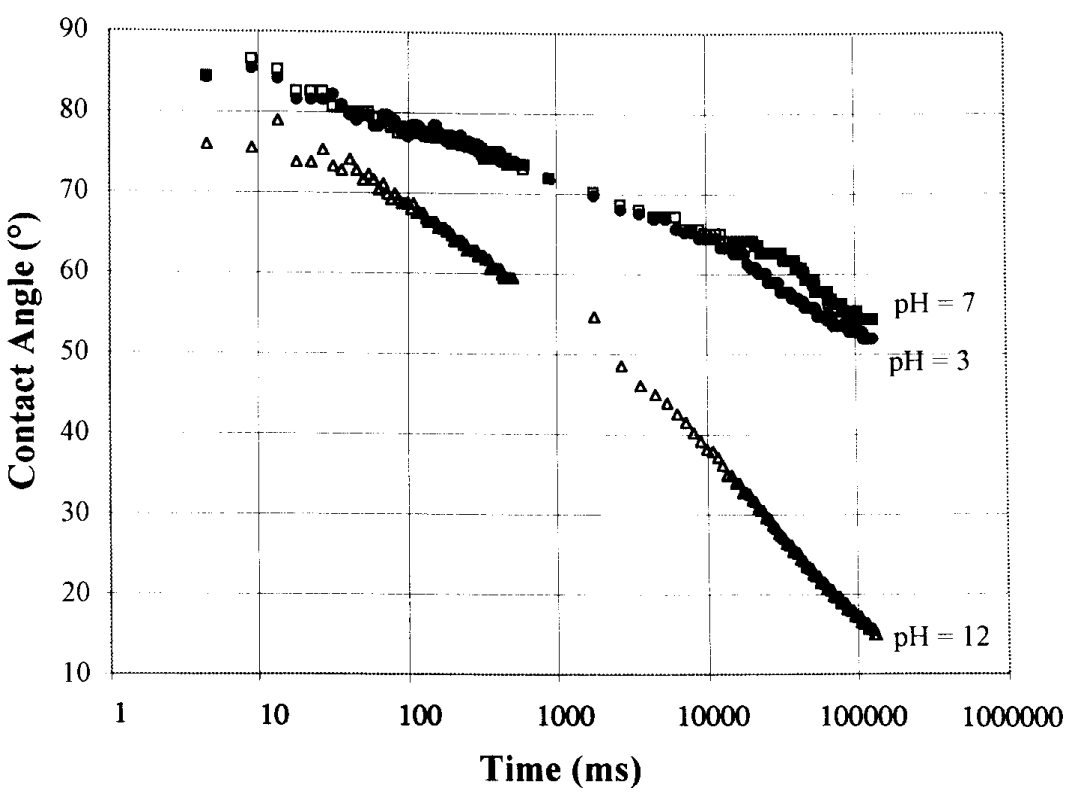

FIG. 5. Short- and long-time evolution of the contact angle of three solutions of different pH deposited on the suberin surface.

Thus, the surface under investigation is characterized by three parameters $\gamma_{\text {sub }}^{\mathrm{LW}}, \gamma_{\text {sub }}^{-}$, and $\gamma_{\text {sub }}^{+} \cdot \gamma_{\text {sub }}^{\mathrm{LW}}$ takes into account not only the London dispersive interactions, but also both dipole/dipole and dipole/induced-dipole interactions. The energy of adhesion is therefore expressed here as

$$
\begin{aligned}
\mathrm{W}_{\mathrm{a}} & =\gamma_{\mathrm{L}}(1+\cos \theta)=W_{\mathrm{a}}^{\mathrm{LW}}+W_{\mathrm{a}}^{\mathrm{AB}} \\
& =2 \sqrt{\gamma_{\text {sub }}^{\mathrm{LW}} \gamma_{\mathrm{L}}^{\mathrm{LW}}}+2 \sqrt{\gamma_{\text {sub }}^{-} \gamma_{\mathrm{L}}^{+}}+2 \sqrt{\gamma_{\text {sub }}^{+} \gamma_{\mathrm{L}}^{-}} .
\end{aligned}
$$

The use of three liquids gave the solution for the three unknowns through the corresponding three equations. The results of this procedure are summarized in Table 2. $\gamma_{\mathrm{sub}}^{\mathrm{AB}}$ reached a significant value of $3.6 \mathrm{mN} \mathrm{m}^{-1}$, arising mostly from a basic character. This result seems highly questionable both with respect to the chemical properties of suberin and in view of the results obtained with water at different $\mathrm{pHs}$ (see below). Furthermore, a total surface energy of 51.2 $\mathrm{mN} \mathrm{m}{ }^{-1}$ seems excessive for such an essentially non-polar material.

\section{The Role of $\mathrm{pH}$}

Three aqueous solutions of $\mathrm{pH} 3,7$, and 12 , respectively, were prepared. Their surface tension were found to be independent of $\mathrm{pH}$. The evolution of the contact angle of these solutions was recorded using both the short- and long-time modes as shown in Fig. 5. Within the short-time range, the plateau values were similar, with a slight decrease for the basic solution, whereas within the longer time range, the decrease in contact angle with time, observed for all $\mathrm{pHs,}$ was drastically enhanced in the case of the basic solution. In fact, in that instance the contact angle reached a zero value after $200 \mathrm{~s}$, whereas those of the neutral and the acidic solutions decreased within that time to a constant value of $50^{\circ}$. This result is direct proof of the predominance of Brønsted acidic sites on the suberin surface, which is hardly surprising given the presence of $\mathrm{COOH}$ functions in the structure of this material. Moreover, the $\mathrm{OH}$ groups, also present in its macromolecules, contribute, albeit to a minor extent, to this acidic character, as with cellulose (15).

\section{Wilhelmy Plate Measurements}

The surface tension of melted suberin showed a linear decrease with temperature as shown in Fig. 6, with a slope of $-0.14 \mathrm{mN} \mathrm{m}^{-1}{ }^{\circ} \mathrm{C}^{-1}$, which is a classical value for organic liquids (16). The extrapolation of these data to $25^{\circ} \mathrm{C}$ gives a value of $37 \mathrm{mN} \mathrm{m}^{-1}$ for the surface tension of suberin, which is slightly lower than that obtained by the contact angle method.

\section{Maximum Bubble Pressure}

The surface tension of liquid suberin as a function of temperature was also measured by the maximum bubble pressure technique. Figure 7 shows again a linear decrease with a slope of $-0.13 \mathrm{mN} \mathrm{m}^{-1}{ }^{\circ} \mathrm{C}^{-1}$, which confirmed the results obtained with the Wilhelmy plate. However, the value of the surface tension extrapolated to $25^{\circ} \mathrm{C}$ was now $45 \mathrm{mN}$ $\mathrm{m}^{-1}$. The difference of $8 \mathrm{mN} \mathrm{m}^{-1}$ between the two methods could probably arises from one of the following factors (or from both): (i) the Wilhelmy plate technique is highly sensitive to surface contaminations of the liquid, whereas the maximum bubble pressure is not; (ii) the first method involves static measurements, that is to say all specific orienta- 


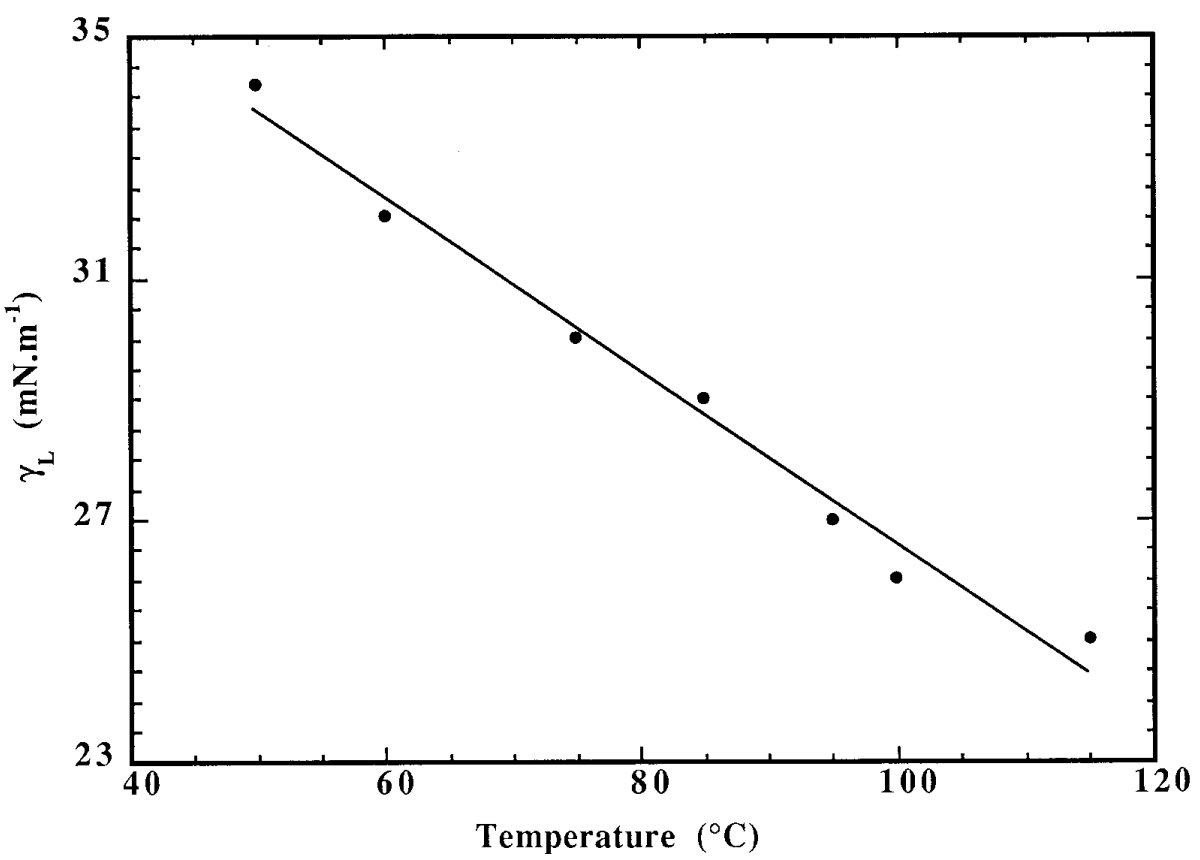

FIG. 6. Determination of the surface energy of the suberin surface as a function of temperature by the Wilhelmy method.

tions or migrations of the more surface-active parts of the suberin macromolecules have been completed, whereas the second involves dynamic measurements during which the air/suberin interface is created on a time scale of about one second and this might not be sufficient for molecular reorientation. Thus, such fresh suberin surfaces would contain more polar groups (and therefore possess a higher energy) than those which have had the time to reach thermody- namic equilibrium involving the predominant presence of non-polar moieties. We are inclined to privilege the latter explanation.

\section{IGC Measurements}

Before recording the results of IGC measurements applied to the surface characterization of suberin, the validity of

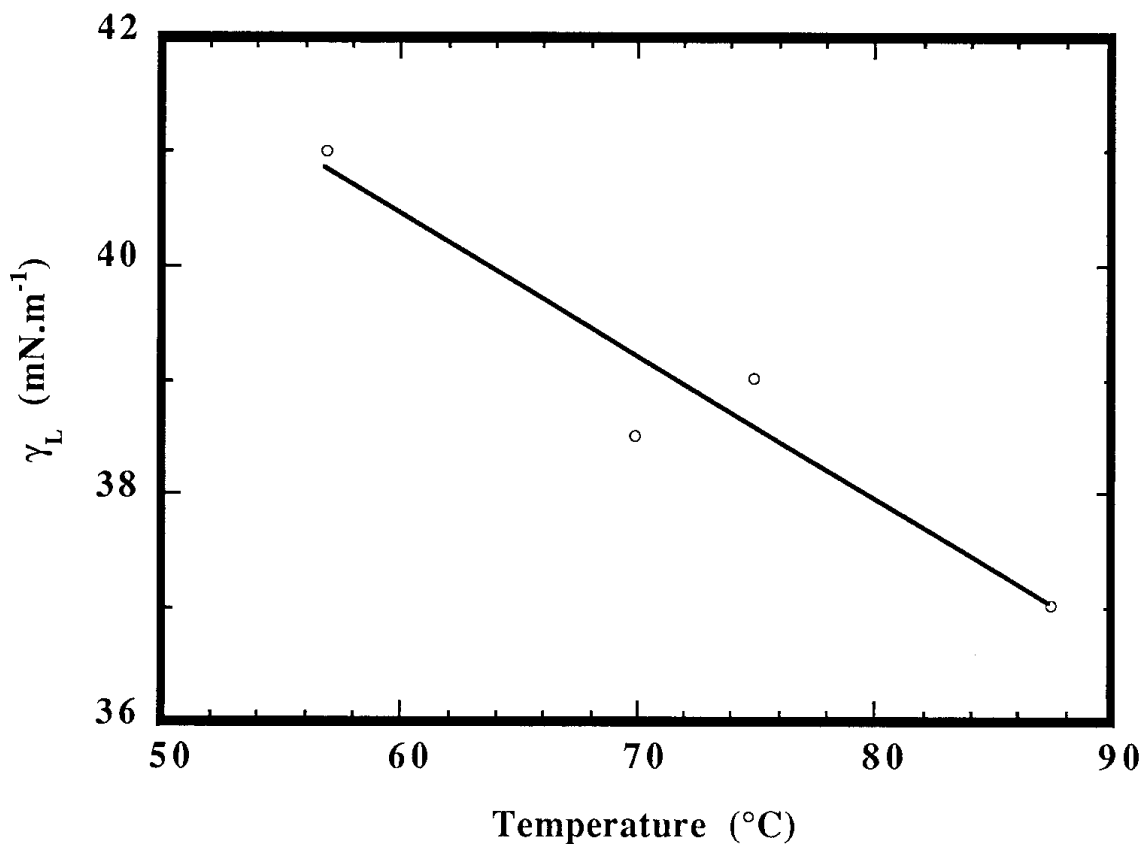

FIG. 7. Determination of the surface energy of the suberin surface as a function of temperature by the maximum bubble pressure method. 
TABLE 4

$\Delta \boldsymbol{G}_{\mathrm{sp}}, \Delta \boldsymbol{H}_{\mathrm{sp}}$, and $\Delta \boldsymbol{S}_{\mathrm{sp}}$ for the Suberin Surface, as Determined by IGC

\begin{tabular}{|c|c|c|c|c|}
\hline Polar probes & $\begin{array}{c}T \\
\left({ }^{\circ} \mathrm{C}\right)\end{array}$ & $\begin{array}{c}\Delta G_{\mathrm{sp}} \\
\left(\mathrm{kJ} \mathrm{mol}^{-1}\right)\end{array}$ & $\begin{array}{c}\Delta H_{\mathrm{sp}} \\
\left(\mathrm{J} \mathrm{mol}^{-1}\right)\end{array}$ & $\begin{array}{c}\Delta S_{\mathrm{sp}} \\
\left(\mathrm{J} \mathrm{mol}^{-1} \mathrm{~K}^{-1}\right)\end{array}$ \\
\hline THF & $\begin{array}{l}50 \\
60 \\
70 \\
80 \\
90\end{array}$ & $\begin{array}{l}5.13 \\
4.97 \\
5.04 \\
5.07 \\
4.92\end{array}$ & 6.12 & 13.62 \\
\hline Chloroform & $\begin{array}{l}50 \\
60 \\
70 \\
80 \\
90\end{array}$ & $\begin{array}{l}5.33 \\
5.26 \\
5.20 \\
5.07 \\
4.92\end{array}$ & 8.58 & 13.51 \\
\hline Ethyl acetate & $\begin{array}{l}50 \\
60 \\
70 \\
80 \\
90\end{array}$ & $\begin{array}{l}4.53 \\
4.54 \\
4.50 \\
4.49 \\
4.45\end{array}$ & 5.21 & 12.35 \\
\hline
\end{tabular}

the application of this method had to be confirmed. Two phenomenological contributions had to be proved negligible with the experimental conditions chosen, namely (i) bulk sorption and (ii) diffusion of probe compounds into the material. This is verified if:

- The chromatographic peaks for polar as well as nonpolar probes are sharp and symmetrical.

- The retention times of the polar and non-polar probes chosen, as well as of propane (the marker), are reproducible.

- The retention times of the probes repeated at the end of an experiment, i.e., after the use of different probes, remain unchanged, thus excluding permanent surface contamination.

All of these conditions were verified for all temperatures with just a modest fluctuation, amounting to less then $1 \%$ for the thermodynamic parameters obtained in this investigation.

The interactions of $n$-alkane probes with suberin are only caused by dispersive forces and $\gamma_{\text {sub }}^{\mathrm{D}}$ can therefore be obtained from the slope of the $R T \ln V n$ vs $a\left(\gamma_{\mathrm{L}}^{\mathrm{D}}\right)^{0.5}$ plot.

Table 3 contains the values of the dispersive component of the surface energy of suberin determined at five different temperatures. The value of $\gamma_{\text {sub }}^{\mathrm{D}}$ extrapolated to $25^{\circ} \mathrm{C}$ was about $48.2 \mathrm{mN} \mathrm{m}^{-1}$. This value is higher than that obtained by contact angle measurements (Table 2), but similar differences have been observed for other materials such as cellulose (15), cork (4), and synthetic polymers (9). As already pointed out in those studies, the higher surface energy values obtained by IGC can be attributed to the absence of problems related to the actual morphology of the liquid/solid interface.

The acid-base properties of the suberin surface were evaluated from its interaction with polar probes at five different temperatures. The corresponding free energies, $\Delta G_{\mathrm{sp}}$, enthalpies, $\Delta H_{\mathrm{sp}}$, and entropies, $\Delta S_{\mathrm{sp}}$, are given in Table 4. From these data and the knowledge of Guttman's numbers ( 8 ) for the probes, the values of $K_{\mathrm{A}}$ and $K_{\mathrm{B}}$ were determined as 0.35 and 0.15 , respectively. The resulting $K_{\mathrm{A}} / K_{\mathrm{B}}$ value of 2.3 implies that suberin has a more pronounced acidic character (expressed here as the sum of Brønsted and Lewis contributions ) and confirms the results obtained with wetting kinetics at different $\mathrm{pHs}$ and are again in contradiction with Van Oss' approach. This ratio is about twice as high as that found for the cork surface (4) probably because in the latter material the suberin is present in the form of a crosslinked polymer bearing ester moieties, rather than carboxylic groups. Moreover, the lower value of surface energy found for cork $\left(38 \mathrm{mN} \mathrm{m}^{-1}\right)$ (4) indicates that the portions of the macromolecules laying on its surface tend to be the long non-polar chains of suberin, a fact that is responsible for the proverbial water repellency of stopcorks.

\section{CONCLUSION}

The results gathered in this multiple approach show a satisfactory coherence which enabled us to draw the conclusion that the suberin we isolated from cork as a paste-like polymer is a substance possessing a rather high surface energy attributed to the various polar functions identified in its structure. Work is in progress to apply the consequences of these results to the correct formulation of novel types of coating materials in which the presence of extracted suberins could play an important surface role.

\section{ACKN OWLEDGMENTS}

We thank the French-Portuguese Scientific Cooperation Programme and JNICT Portugal for financial support, the Champcork Company for the gift of cork samples, and Dr. Joëlle Collomb of BP France for kindly providing us with a virgin PE support.

\section{REFERENCES}

1. Pereira, H., Wood Sci. Technol. 22, 211 (1988).

2. Kolattukudy, P. E., in "Biochemistry of Wounded Plant Tissues", p. 43. Walter Gruyter \& Co., Berlin, 1978.

3. Holloway, P. J., Chem. Phys. Lipids 6, 158 (1972).

4. Cordeiro, N., Pascoal Neto, C., Gandini, A., and Belgacem, M. N., J. Colloid Interface Sci. 174, 246 (1995).

5. Cordeiro, N., Pascoal Neto, C., Belgacem, M. N., and Gandini, A., in preparation.

6. Pascoal Neto, C., Cordeiro, N., Seca, A., Domingues, F., Gandini, A., and Robert, D., Holzforschung 50, 563 (1996).

7. Aurenty, P., Schroeder, A., Jallu, J., Gandini, A., and Tessadro A., 
TAGA Proceedings, 1995, p. 915 and 1170; Aurenty, P., Lanet, V., Tessadro, A., and Gandini, A., Rev. Sci. Inst., in press.

8. Gutmann, V., “'The Donor-Acceptor Approach to Molecular Interactions.'’ Plenum Press, New York, 1978.

9. Lloyd, D. R., Ward, T. C., and Schreiber, H. P., "'Inverse Gas Chromatography.' ACS Symposium Series 391, American Chemical Society, Washington, D.C., 1989.

10. Lester, G. R., J. Colloid Interface Sci. 16, 315 (1961).

11. Fowkes, F. M., Riddel, F. L., Pastore, W. E., and Weber, A. A., Colloids Surfaces 43, 367 (1990).
12. Ström, G., Fredriksson, M., and Klason, T., J. Colloid Interface Sci. 123, 324 (1988).

13. Kato, Y., Fowkes, F. M., and Vanderhoff, J. W., Ind. Eng. Chem. Prod. Res. Dev. 21, 441 (1982).

14. Van Oss, C. J., in "Polymer Surfaces and Interfaces" (Feast, W.J., Munro, H. S., and Richards, R. W., Eds.) Chapter 11, p. 267. John Wiley \& Sons, New York, 1993.

15. Belgacem, M. N., Czeremuszkin, G., Sapieha, S., and Gandini, A., Cellulose 2, 145 (1995).

16. Wu, S., "Polymer Interface Science and Adhesion."' M. Dekker Inc., New York, 1982. 